\title{
Water from Air: Desiccant System Design and Simulation
}

\author{
Aayush Bendre, Hardik Birla, Chetan Choudhary, Gayatri Potbhare, Burhanuddin Jawadwala \\ and Satish Inamdar
}

\begin{abstract}
Air water generators that harvest water from air humidity have the potential to counter the ever-rising problem of drinking water scarcity. There are many different types of air water generation systems that work on various different principles. Desiccant based air water generation systems work on the principle of moisture absorption, consisting of a packed bed dehumidifier that absorbs the moisture from air. This reduces the energy requirement of the system. To discuss the efficiency of the system, it is crucial to understand the working of the packed bed column. In this paper, a mathematical model has been developed for a packed bed dehumidification system using aqueous $\mathrm{CaCl}_{2}$ as the liquid desiccant. This model has been developed using water saturation pressure and equilibrium relative humidity models. The packed bed model has been used to study the effect of various input parameters like air and desiccant flow rate, packing material, relative humidity and desiccant concentration, on the capacity of the desiccant to absorb water from air. The results so obtained can be used to predict the water that can be absorbed by the desiccant in the packed bed column for given inlet conditions.
\end{abstract}

Index Terms - Moisture, Desiccant, Packed Bed Column, Saturation, Relative Humidity.

\section{INTRODUCTION}

Freshwater scarcity has become a major restraint to socio-economic development thus endangering sustainable development of human society. Due to population growth, economic development and climate change, water is becoming increasingly scarce in many parts of the world. Scarcity of fresh water can have a deleterious impact on the world leading to many health and economic problems. Lack of access to drinking water, hunger, lack of education, diseases, sanitation issues, poverty and migration are some of the effects of fresh water scarcity.

When we talk about scarcity of fresh water, it is not only an issue of water availability, but also of the quality of available water. Prolonged droughts and rising temperatures put strain on water resources and also lead to degradation of water

Manuscript revised on April 30, 2021, published on May 10, 2021

Aayush Bendre, Hardik Birla, Chetan Choudhary, Gayatri Potbhare,Burhanuddin Jawadwala and Satish Inamdar, Chemical Engineering Department, Vishwakarma Institute of Technology, 666, Upper Indiranagar, Bibwewadi, Pune 411037, INDIA.. resources [1]. A study by Mekonnen and Hoekstra [2] have shown that about 0.5 billion people around the world experienced annual severe water scarcity in the years 1996-2005.

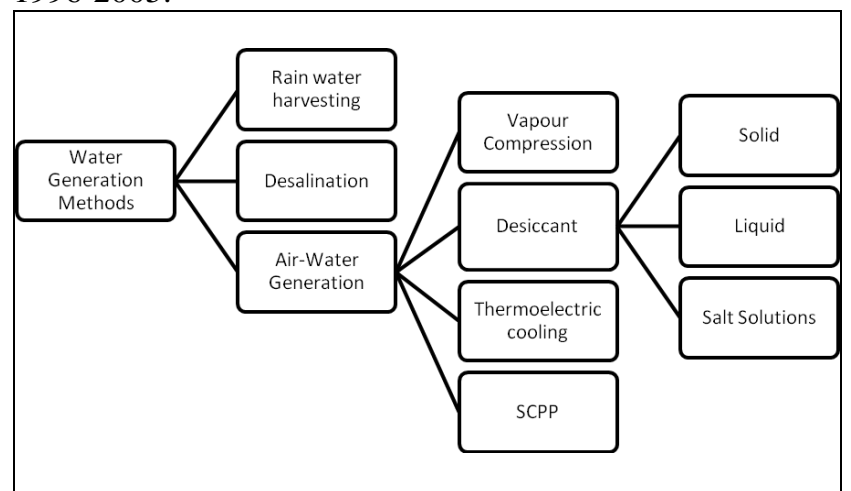

Figure-1: Water Generation Methods.

The World Health Organization (WHO) has estimated that 1.1 billion people worldwide are without access to safe potable water [3]. Many efforts are being made to solve this problem. Figure 1shows several methods used for generation of drinking water.

As per studies the total amount of water available today will be enough to provide for current population minimally. However, the uneven distribution of water sources has made the resources precious in certain countries [4]. Rapid population growth and an increasing consumption of water per capita has aggravated this problem further.

The atmosphere is estimated to contain more than $12.9 \times[10]$ $\wedge 12 \mathrm{~m} 3$ of water in the form of water vapour out of which approximately $99.13 \%$ of it is contained in the troposphere [5]. During past decades, Air-Water generation technology has received great attention around the world. Numerous studies have been conducted on various methods that can be utilised to generate water from air (see Figure 1). Wahlgren[6] reviewed various atmospheric water generation designs. These included designs based on surface cooling, desiccant based and convection induced.

A study conducted by Anbarasu and Pavithra [7]reported the design of a device to generate drinking water from humid air using the traditional vapour compression method. This method depends on lowering the temperature of air below its dew point, which is achieved using the vapour compression cycle. Nandyet. al.[8]discussed the method to develop an air water generator using thermoelectric couple. Using the Peltier effect to create a heat flux, it brings heat from one side of the device to the other, reducing the temperature on one side [6]. Ming, et. al. [9] proposed a solar chimney power plant (SCPP) for solar thermal power generation along with 
freshwater extraction from humid air. The air flows upward inside the chimney guided by convection. As air rises, its temperature decreases due to reduced internal energy converting to gravitational potential energy. When the temperature falls below the dew point or reaches saturation temperature, the water vapour in the moist air will begin to condense.

The afore mentioned methods work on the principle of reducing the temperature of air below its dew point to condense the water vapour, thus increasing the cost of water generation. Many new methods are being developed to figure out a way to reduce the energy cost of air-water generation. Bergmair et. al. [10] conducted a system analysis for air water generation using water vapour selective membranes. The study showed that the method can reduce energy requirement of water extraction by more than $50 \%$. However, the manufacturing of such special membranes brings extra costs. This is avoided in desiccant based systems which work on absorption of moisture by a desiccant material, which are usually cheap. In dehumidifiers, a study showed that [11] using desiccant based system rather than vapour compression cycle reduces the energy cost by $60 \%$. Another advantage of desiccant based systems is its easier integration with solar energy. Qi et. al. [12] have studied the integration of solar absorbers with ionic liquid-based sorbent thus making a solar based atmospheric water generator with simultaneous adsorption-desorption process.

The desiccants can be either solid or liquid or in the form of salt solutions. Numerous liquid desiccants are commercially available like triethylene glycol, diethylene glycol and ethylene glycol, salt solutions like calcium chloride, lithium chloride and lithium bromide can also be used as desiccants. Calcium chloride, $\mathrm{CaCl}_{2}$, is a good candidate since it has good desiccant characteristics and does not vaporize in air at ambient conditions. A study by Srivastava and Yadav [13] compared the water generation capacity from air using three composite materials namely $\mathrm{LiCl} /$ sand, $\mathrm{CaCl}_{2} /$ sand and $\mathrm{LiBr} / \mathrm{sand}$. The results showed that $\mathrm{CaCl}_{2} /$ sand composite material provided superior performance than the others along with lesser cost. A method was suggested by Xiu-Wei, et. al. [14] to determine the ratio selection of mixed liquid desiccant consisting of $\mathrm{LiCl}-\mathrm{CaCl}_{2}$ solution. For this the non-random two-liquid NRTL equation of state was used. The results showed that as compared to a single $\mathrm{LiCl}$ solution, the dehumidification effect can be raised by more than $20 \%$ with a mixed desiccant.

A typical desiccant air water generation system consists of a packed bed dehumidifier, a regenerator tank and a water treatment and remineralizer unit. The dehumidifier unit plays a crucial role in determining the efficiency of the entire air water generation system as the moisture is absorbed in this phase. So, it is imperative to study the working of the dehumidification unit and the parameters on which it depends. This can be achieved by the development of a mathematical model. A study by Liu et. al. [15] developed empirical correlations to predict dehumidifier performance of a liquid desiccant-based air conditioning system. Another study by Abdul-Wahab et. al. [16] included the development of a mathematical model to predict the moisture removal rate and dehumidification effectiveness for structured liquid desiccant air dehumidifier using triethylene glycol as desiccant. Luo et. al. [17] in their work reviewed various mathematical models for predicting heat and mass transfer in liquid desiccant dehumidifiers. They compared models for adiabatic dehumidifiers, like finite difference model and simplified model. Along with these, they also considered models that were independent of film thickness, models based on uniform film thickness and models based on variable film thickness. Jain and Bansal [18] studied the performances of liquid desiccant dehumidification systems. A comparative study was done for HVAC systems with three commonly used desiccants namely, lithium chloride, calcium chloride and ethylene glycol. Similarly, Chung [19] had conducted a study for predicting the efficiency of moisture removal in packed bed dehumidification systems. The study focused on lithium chloride and TEG desiccants. Very few studies have focused on the modeling of a liquid desiccant based, packed bed dehumidifier for air water generation using $\mathrm{CaCl}_{2}$ liquid desiccant.

For developing a mathematical model for the packed bed dehumidifier, it is necessary to study the heat and mass transfer coefficients of the system. In 1968, Onda et. al. [20] studied the mass transfer coefficient between gas and liquid phases in packed columns. They presented the empirical equations for liquid-side and gas-side mass transfer coefficients. Later, another study by Gandhidasan et. al. [21] focused on calculation of heat and mass transfer coefficients for a desiccant-air contact packed tower. This study consisted of aqueous $\mathrm{CaCl}_{2}$ used as desiccant and Ceramic Raschig rings and Berl saddles used as packing material. On a similar note, a study was conducted by Oberg et. al. [22] for the same using triethylene glycol as desiccant and for high liquid flow rates. Along with heat and mass transfer coefficients, the interfacial area also plays an important role in the development of the mathematical model. A study by Gandhidasan [23] focused on the estimation of effective interfacial area in a packed bed liquid desiccant contactor. In this study, effects of various factors like air mass flux, air density and shape of random packing has been discussed.

This paper focuses on the development of a mathematical model for a packed bed dehumidifier using $\mathrm{CaCl} 2$ solution as desiccant. To fulfil this objective, it is important to initially study the vapour pressure models of desiccant $\left(\mathrm{CaCl}_{2}\right.$ solution) at various concentrations. This is done in the first part of the paper. Later, the heat and mass transfer equations are used along with the vapour pressure model to form the mathematical skeleton of the model. These equations are simultaneously solved to evaluate the amount of water absorbed by the solution using shooting method. The effects of changing the air and desiccant flow rates, air humidity, desiccant concentration and the packing material are reviewed and the results are analysed.

\section{Mathematical Model}

The performance of the packed bed dehumidifier greatly depends on the packing material, the desiccant flow rate, the air flow rate and the column dimensions. The absorption of the packed bed will directly affect the performance of the air water generation. Thus, a mathematical model was generated. Figure 2 shows the schematic of the process in which air flows from the bottom of the packed bed in a counterflow direction to the liquid desiccant. The packing material is used 
to increase the mass transfer area between the air and the liquid desiccant. The mass and heat transfer process equations for the packed bed are derived in terms of the air humidity ratio $(W)$, the liquid desiccant moisture content $(Y)$ and the temperature of both air and liquid desiccant.

The equations are derived on basis of assumptions [24]:

1. Flow is one-dimensional in the direction of bed height.

2. Steady state of processes are considered.

3. Properties of both air and liquid desiccant are constant.

4. Heat and mass transfer coefficients are constant.

The balance for moisture content in air $(W)$ and in liquid desiccant $(Y)$ is done over a control volume of height $\mathrm{dx}$

$$
\begin{aligned}
& \frac{d W}{d x}=\frac{\rho_{a} k A_{x}}{G_{a}^{r}}\left(W_{e}-W\right) \\
& \frac{d y}{d x}=\frac{\rho_{a} k A_{x}}{G_{1}^{r}}\left(W_{e}-W\right)
\end{aligned}
$$

Similarly, energy balance is done over the control volume to give

$$
\left(C_{p a}+W C_{p v}\right) \frac{d T_{a}}{d x}+C_{p v} \frac{d W}{d x}\left(T_{a}-T_{r e f}\right)+\frac{h A_{x}}{G_{a}^{\prime}}\left(T_{a}-T_{0}\right)=
$$

0

$$
\begin{aligned}
& \left(C_{p l}+Y C_{p w}\right) \frac{d T_{1}}{d x}+C_{p w} \frac{d Y}{d x}\left(T_{1}-T_{r e f}\right)+\frac{h A_{x}}{G_{1}^{t}}\left(T_{a}-T_{1}\right)+ \\
& \frac{d Y}{d x} q_{b}-\frac{\rho_{a} k A_{g} \lambda}{G_{l}^{t}}\left(W_{\theta}-W\right)=0
\end{aligned}
$$

The resulting first order, nonlinear differential equations are solved to calculate the variation of $\mathrm{W}, \mathrm{Y}, \mathrm{T}_{\mathrm{a}}$ and $\mathrm{T}_{1}$ along the bed height subjected to the following boundary conditions

$$
\begin{aligned}
& a t x=0 ; W=W_{\mathfrak{i}}, T_{a}=T_{a i} \\
& a t x=L ; Y=Y_{\mathfrak{i}}, T_{\mathbb{I}}=T_{\mathfrak{i f}}
\end{aligned}
$$

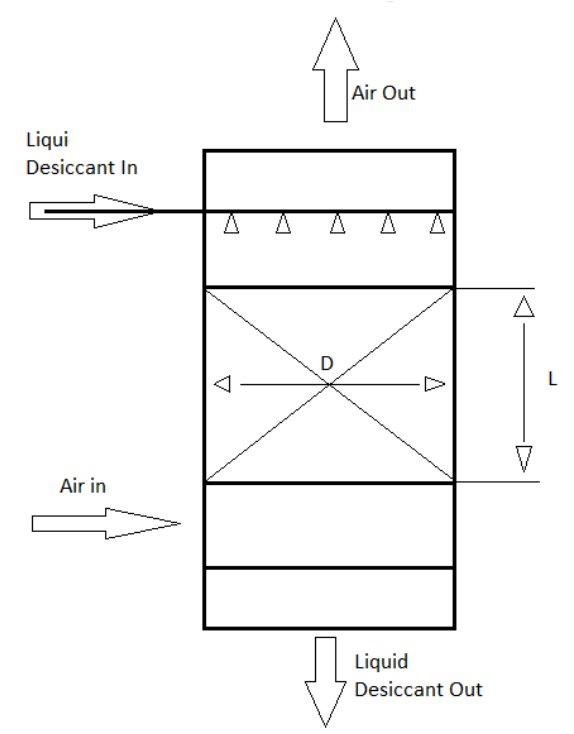

Figure 2. Liquid Desiccant Packed Bed Dehumidifier.

We use simplified parameters for the purpose of calculations. The equations 1-4 are rewritten in terms of simplified parameters as follows:

$$
\frac{d W}{d x}=a_{1}\left(W_{e}-W\right)
$$

$$
\begin{gathered}
\frac{d Y}{d X}=a_{2}\left(W_{a}-W\right) \\
\frac{d T_{a}}{d x}=\frac{-a_{5}\left(T_{a}-T_{1}\right)-a_{1} a_{4} T_{a}\left(W_{2}-W\right)}{1+a_{4} W} \\
\frac{d T_{1}}{d x}=\frac{a_{3}\left(W_{8}-W\right)-a_{7}\left(T_{a}-T_{1}\right)-a_{2} a_{8} T_{1}\left(W_{8}-W\right)}{1+a_{8} Y}
\end{gathered}
$$

The equations are subject to boundary conditions:

$$
\begin{aligned}
& a t X=0 ; W=W_{\mathrm{i},}, T_{a}=T_{a \mathrm{i}} \\
& a t X=1 ; Y=Y_{\mathrm{i}} T_{\mathbb{1}}=T_{\mathrm{li}}
\end{aligned}
$$

Dimensionless variables and parameters are given as,

$$
\begin{aligned}
& X=\frac{x}{L} \quad a_{1}=\frac{\rho_{a} k A_{x} L}{G_{a}^{f}} \quad a_{2}=\frac{P_{a} k A_{x} L}{G_{I}^{r}} \\
& a_{a}=a_{2} \frac{\pi}{c_{p l}} \quad a_{4}=\frac{c_{p v}^{a}}{C_{p a}} \quad a_{5}=\frac{\hbar A_{x} L}{G_{a}^{r} C_{p a}} \\
& a_{6}=\frac{C_{p w}}{c_{p l}} \quad a_{7}=\frac{h_{A} L}{G^{r} C_{p l} I} \text {. }
\end{aligned}
$$

The value of $\mathrm{W}_{\mathrm{e}}$ can be calculated by the perfect gas relation for moist air given by

$$
W_{e}=0.62185 \frac{P_{s}}{P-P_{s}}=0.62185 \frac{\oplus P_{W}}{P-\Phi P_{W}}
$$

Where $P_{w}$ is the saturation pressure of water vapour and $\phi$ is the equilibrium relative humidity of air. The relation between moisture content of $\mathrm{CaCl}_{2}$ solution (Y) and the equilibrium relative humidity of air $(\phi)$ is obtained from [25].

$\phi=0.2452+0.4224(\ln (Y))$

The saturation pressure of water vapour $\left(\mathrm{P}_{\mathrm{w}}\right)$ is given in terms of dry bulb temperature of air by the correlation $P_{W}=0.2785+0.1 T_{a}-0.002 T_{a}{ }^{2}+10^{-4} T_{a}{ }^{a}$

(14)

The differential equations (6)-(9) represent a two-point boundary value problem with four first order, nonlinear differential stiff equations, between $X=0$ and $X=1$.These were solved using the 3(2) Pair of Runge -Kutta integration scheme [26]. Shooting method was utilised for getting the values of $\mathrm{Y}$ and $\mathrm{T}_{1}$ at $\mathrm{X}=0$ to a tolerance of $10^{-10}$.

The values of $k, h$ and $A_{s}$ are calculated using correlations reported by Treybal [27] at an average temperature of $35^{\circ} \mathrm{C}$ for both air and $\mathrm{CaCl}_{2}$ solution.

\section{RESULTS AND DISCUSSION}

The present work discusses the different models for estimating saturation pressure of water that can be used for its utilization in the Eq. 12. Along with this, the models for estimating equilibrium relative humidity are also compared. The absorption of water by the desiccant is studied by varying:
1) Inlet relative humidity
2) Packing Material
3) Inlet air flow rate
4) Inlet desiccant flow rate
5) Inlet desiccant concentration

The dimensions of the packed bed are kept constant. Height of the packed bed is $0.3 \mathrm{~m}$ and diameter is $0.2 \mathrm{~m}$. All the results of the various runs are listed in Table-2.

\section{a) Water Saturation Pressure Model}

The cubic model for saturation pressure of water developed in this paper (Eq. 14) is compared with the models developed by Hammad [28] and Radhwan [24] along with standard models such as Wexler and ITS-90 [29]. 


\section{Available online at www.ijrat.org}

The ITS-90 is used as the base for comparison. Fig. 3 shows a very good fit for the suggested cubic model with the ITS-90 model for temperatures in the range of $10^{\circ} \mathrm{C}$ to $55^{\circ} \mathrm{C}$. The ITS-90 model is the most accurate, however, it is complex and would increase computation cost for the mathematical model. The cubic model developed is simpler and emulates the estimation of saturation pressure of water by ITS-90 efficiently, thus being a good alternative to be used in the mathematical model.

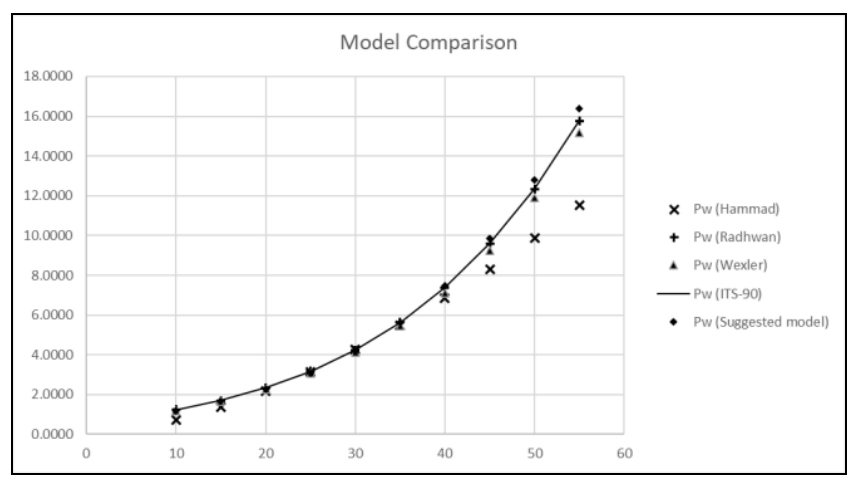

Figure-3: Comparison of Saturation Pressure Models

\section{(b) Relative Humidity Model}

Equilibrium relative humidity $(\phi)$ is estimated as a function, shown in Eq. 13, of desiccant concentration $(Y)$, to be used along with the saturation vapour pressure of water model, to determine the equilibrium humidity of the desiccant. This model is compared with models by Radhwan [24] and Hammad [28].

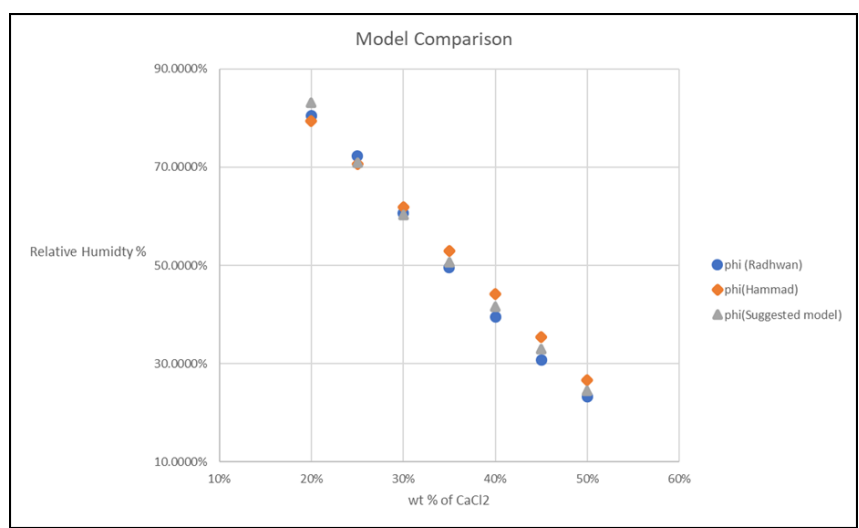

Figure 4. Comparison of Equilibrium Humidity Models.

The model developed in this paper shows an average $4 \%$ deviation from the model developed by Radhwan [24], and a $5 \%$ deviation from the model developed by Hammad [28].

\section{c) Effect of Inlet Relative Humidity}

The inlet relative humidity will play an important role in determining the amount of water that is absorbed by the desiccant.In Fig. 5a it can be seen that with decreasing relative humidity the water absorbed by the desiccant $(45$ wt $\%$ ) goes on decreasing. This can be attributed to the decrease in concentration gradient as air humidity decreases, thus reducing the mass transferbetween the desiccant and air. If the gradient decreases further, it will lead to evaporation instead of absorption, thus humidifying the air. This is shown in Fig. $5 \mathrm{~b}$ where theinlet desiccant concentration is reducedto $30 \mathrm{wt} \%$. It is seen that below $60 \%$ relative humidity, the $\mathrm{Y}$ value at $X=0(x=0$; outlet $)$ goes below the $Y$ value at $X=1$ ( $\mathrm{x}=\mathrm{L}$; inlet). This characteristic of the model can help suggest the boundary conditions within which the system must be operated so as to absorb water from air.

\begin{tabular}{|c|c|c|c|}
\hline $\begin{array}{c}\mathrm{CaCl}_{2} \\
\text { Weight }\end{array}$ & $\begin{array}{c}\phi \\
\text { (Radhwan }\end{array}$ & $\begin{array}{c}\phi \\
\text { (Hammad } \\
\text { Model) }\end{array}$ & $\begin{array}{l}\phi \\
\text { (Suggested } \\
\text { Model) }\end{array}$ \\
\hline $20 \%$ & 0.805185 & 0.794 & 0.8307707 \\
\hline $25 \%$ & 0.722255 & 0.706 & 0.7092538 \\
\hline $30 \%$ & 0.6069127 & 0.618 & 0.6030986 \\
\hline $35 \%$ & 0.4951105 & 0.53 & 0.5066821 \\
\hline $40 \%$ & 0.3951725 & 0.442 & 0.4164684 \\
\hline $45 \%$ & 0.3079103 & 0.354 & 0.3299633 \\
\hline $50 \%$ & 0.232095 & 0.266 & 0.2452 \\
\hline \multicolumn{2}{|c|}{ Table . Equilibrium Relative Humidity Comparison. } \\
\end{tabular}

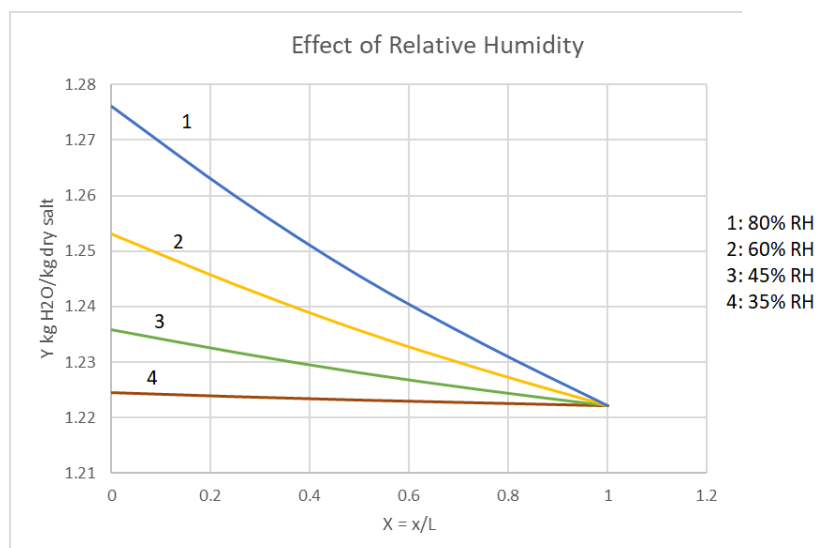

Fig. 5a.Y profile; Effect of varying inlet relative humidity; $\mathrm{CaCl} 2$ concentration: $45 \mathrm{wt} \%$; Temperature: $30 \mathrm{oC}$; Air flow rate: $95 \mathrm{cfm}$; Liquid Desiccant flow rate: 500 lph; Packing Material: 25 mm Ceramic Raschig Rings.

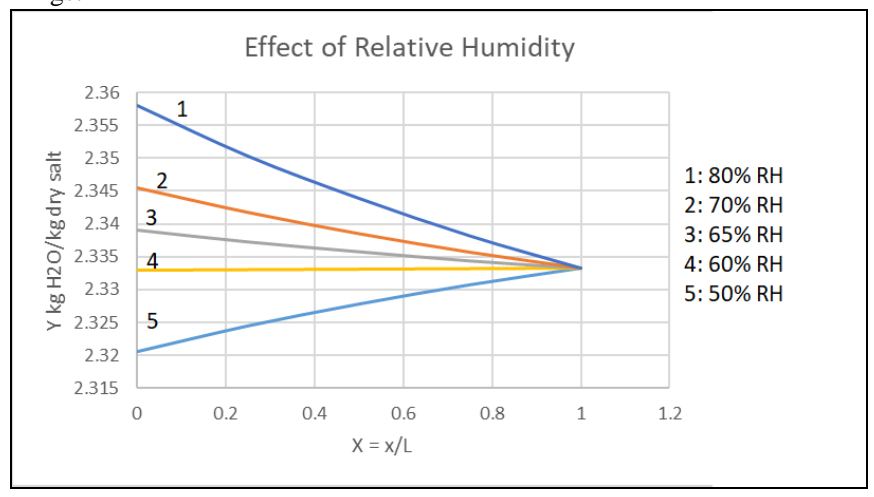

Fig. 5b: Y profile; Effect of varying inlet relative humidity; $\mathrm{CaCl} 2$ concentration: $30 \mathrm{wt} \%$; Temperature: $30 \mathrm{oC}$;Air flow rate: $95 \mathrm{cfm}$; Liquid Desiccant flow rate: $500 \mathrm{lph}$; Packing Material: $25 \mathrm{~mm}$ Ceramic Raschig Rings. 


\section{Available online at www.ijrat.org}

\section{d) Effect of Packing Material}

The packing material plays a crucial role in the absorption of water; it provides increased interfacial area, improving the area of contact between air and desiccant enhancing the mass transfer. Thus, it is important to study the way different packing materials affect the water content absorbed by the desiccant. From figure-7, it can be seen that the Carbon Raschig rings provide the largest area of contact, leading to maximum absorption of water.

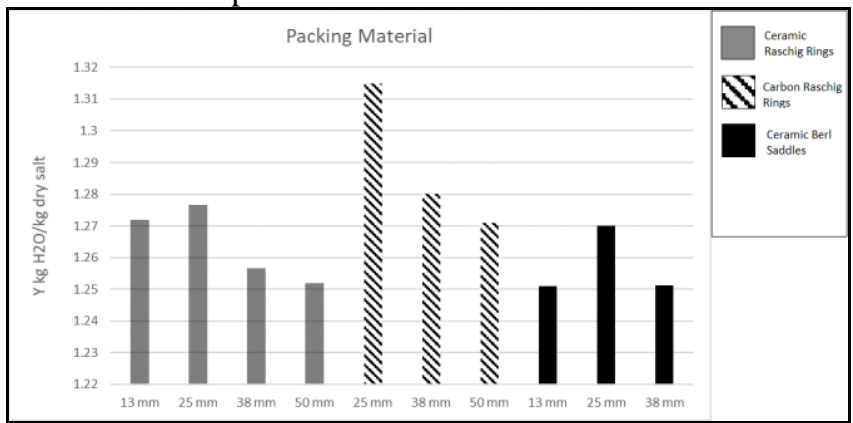

Fig. 6: Bar Graph; Effect of Packing Material on water absorbed; $\mathrm{CaCl} 2$ concentration: $45 \mathrm{wt} \%(\mathrm{Y}=1.222)$; Temperature: 30oC; Air flow rate: 95 cfm; Liquid Desiccant flow rate: 500 lph; Relative Humidity: 60\%.

\section{e) Effect of Inlet Desiccant Flow Rate}

Fig. 8ashows that by decreasing the desiccant flow rate, the outlet water content in desiccant $(\mathrm{Y})$ goes on increasing. By decreasing the desiccant flow rate, the time of contact between water molecules in air and the desiccant increases, thus giving enough time for absorption. The desiccant flow rate ranges from 400-600 $\mathrm{lph}$, for which the final water content in desiccant ranges from $1.26-1.2455 \mathrm{~kg} \mathrm{H} 2 \mathrm{O} / \mathrm{kg}$ dry salt.

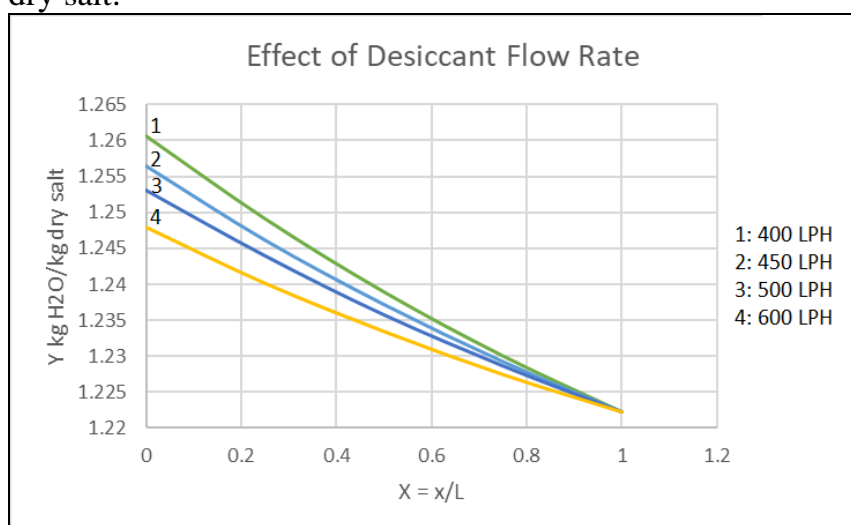

Fig. 7a: Y profile; Effect of varying inlet desiccant flow rate; $\mathrm{CaCl} 2$ concentration: $45 \mathrm{wt} \%$; Temperature: $30 \mathrm{oC}$; Air flow rate: $95 \mathrm{cfm}$; Packing Material: $25 \mathrm{~mm}$ Ceramic Raschig Rings; Relative Humidity: 60\%.

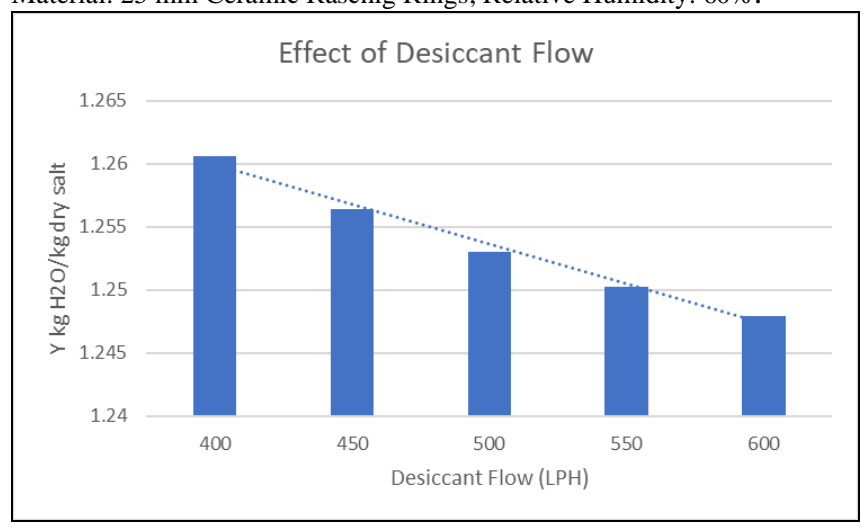

Fig. 7b: Bar graph; Effect of varying inlet desiccant flow rate; $\mathrm{CaCl} 2$ concentration: $45 \mathrm{wt} \%$; Temperature: $30 \mathrm{oC}$; Air flow rate: $95 \mathrm{cfm}$; Packing Material: 25 mm Ceramic Raschig Rings; Relative Humidity: 60\%.

\section{f) Effect of Inlet Air Flow Rate}

The effect of varying inlet air flow rate on the water absorption by desiccant is shown by Figs. 9a and 9b. The increase in air flow rate increases the outlet water content in desiccant (Y). As the air flow rate increases the water amount entering the column goes on increasing. Comparing with the effect of varying inlet desiccant flow rate (Figs. 8a and 8b), air flow rate has a lesser effect on the absorption capacity. Y varies between $1.27-1.28 \mathrm{~kg} \mathrm{H} 2 \mathrm{O} / \mathrm{kg}$ dry salt for a change in air flow rate between $65-130 \mathrm{cfm}$.

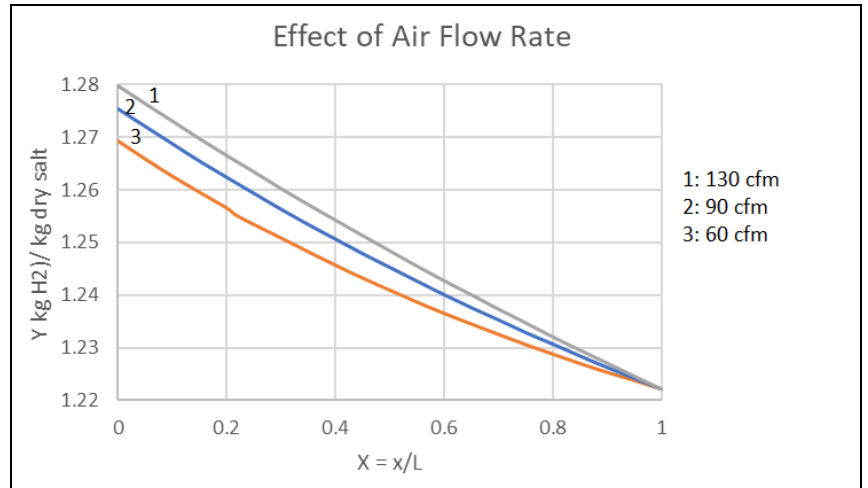

Fig. 8a: Y profile; Effect of varying inlet air flow rate; $\mathrm{CaCl} 2$ concentration: $45 \mathrm{wt} \%$; Temperature: 30oC; Desiccant flow rate: 500 lph; Packing Material: 25 mm Ceramic Raschig Rings; Relative Humidity: 80\%.

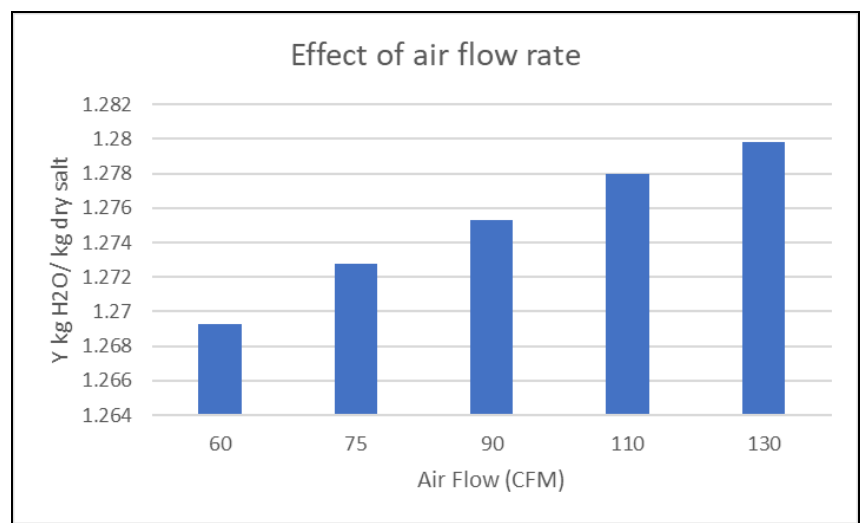

Fig. 8b: Bar graph; Effect of varying inlet air flow rate; $\mathrm{CaCl} 2$ concentration: $45 \mathrm{wt} \%$; Temperature: $30 \mathrm{oC}$; Desiccant flow rate: $500 \mathrm{lph}$; Packing Material: 25 mm Ceramic Raschig Rings; Relative Humidity: $80 \%$.

\section{g) Effect of Desiccant Concentration}

The effect of desiccant concentration on water absorbed is shown in Fig. 10. The bar graph represents the difference in Yin and Yout for an inlet relative humidity of $60 \%$. It can be seen that with increase in desiccant concentration, the $\Delta \mathrm{Y}$ increases. For lower concentration, i.e., more initial water content in the desiccant, the $\Delta \mathrm{Y}$ becomes negative suggesting that the water gets evaporated. This can help us understand the feasibility of using the desiccant of a particular concentration for particular humidity conditions.

Inlet relative humidity plays an important role in determining the amount of water absorbed. It also determines, whether the water will be absorbed in the desiccant or be evaporated from the desiccant. $\mathrm{Y}(\mathrm{X}=0)>\mathrm{Y}(\mathrm{X}=1)$ will mean that water is absorbed by the desiccant; as it is a counter-current operation, 
desiccant enters at $\mathrm{X}=1$ and leaves at $\mathrm{X}=0$. If $\mathrm{Y}(\mathrm{X}=0)$ $<\mathrm{Y}(\mathrm{X}=1)$ (as shown in Fig. 5b), it would mean that the desiccant lost some of its moisture to air, that is the water evaporated. Same can be seen in the case of lowering desiccant concentration, where initial moisture content is great, the water evaporates from the liquid desiccant humidifying the air.

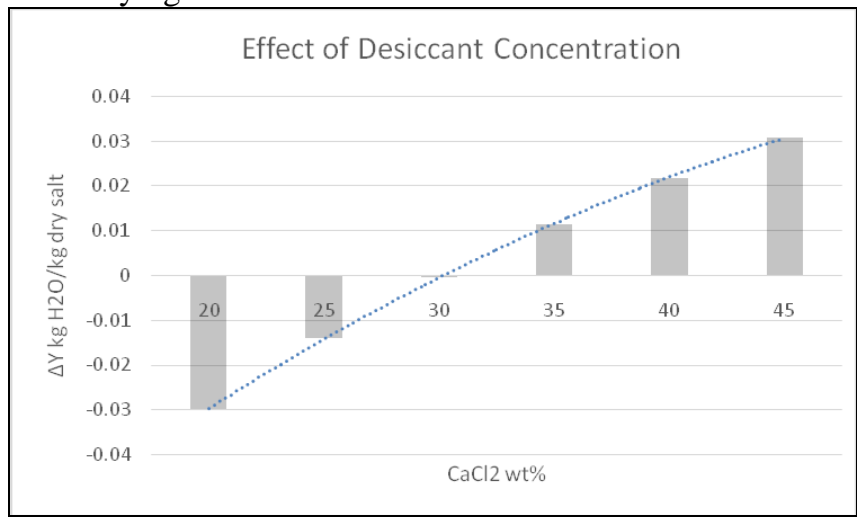

Fig. 9: Bar graph; Effect of varying inlet desiccant concentration; Air flow rate: $95 \mathrm{cfm}$; Temperature: 30oC; Desiccant flow rate: 500 lph; Packing Material: 25 mm Ceramic Raschig Rings; Relative Humidity: 60\%.

\section{Conclusion}

A mathematical model is presented to predict the performance of a packed bed operating with counterflows of air and calcium chloride as a liquid desiccant. For the model, using material data sheets, models have been generated for calculating saturation vapour pressure and equilibrium relative humidity. These models are compared with various other models in literature, to check for accuracy. The packed bed model is used to study the effect of various factors such as air flow rate, desiccant flow rate, relative humidity and packing material are studied.

The results have shown that the increase in desiccant flow rate, $\mathrm{Y}_{\text {out }}$ decreases, while with the increase in air flow rate, $\mathrm{Y}_{\text {out }}$ increases. The effect of packing material on water absorption is also studied. The Carbon Raschig Rings provide with the maximum interfacial area, thus increasing the absorption of water by the desiccant.

\section{Notation.}

\begin{tabular}{|c|c|c|}
\hline $\mathrm{A}_{\mathrm{s}}$ & $\begin{array}{l}\text { transfer area (of heat and mass) } \\
\text { per unit volume of bed }\end{array}$ & $\mathrm{m}^{2} / \mathrm{m}^{3}$ \\
\hline $\mathrm{a}$ & Dimensionless parameters & - \\
\hline $\mathrm{C}_{\mathrm{pa}}$ & $\begin{array}{l}\text { specific heat at constant pressure } \\
\text { for air }\end{array}$ & $\mathrm{J} / \mathrm{kg} \cdot \mathrm{K}$ \\
\hline $\mathrm{C}_{\mathrm{pl}}$ & $\begin{array}{l}\text { specific heat at constant pressure } \\
\text { for liquid desiccant }\end{array}$ & J/kg.K \\
\hline $\mathrm{C}_{\mathrm{pv}}$ & $\begin{array}{l}\text { specific heat at constant pressure } \\
\text { for water vapour }\end{array}$ & $\mathrm{J} / \mathrm{kg} \cdot \mathrm{K}$ \\
\hline $\mathrm{C}_{\mathrm{pw}}$ & $\begin{array}{l}\text { specific heat at constant pressure } \\
\text { for water }\end{array}$ & $\mathrm{J} / \mathrm{kg} \cdot \mathrm{K}$ \\
\hline W & air humidity ratio & $\mathrm{kg} \mathrm{H}_{2} \mathrm{O} /$ \\
\hline $\mathrm{W}_{\mathrm{e}}$ & Equilibrium air humidity ratio & $\begin{array}{l}\text { kg dry air } \\
\text { kg H } \mathrm{H}_{2} \mathrm{O} / \\
\text { kg dry air }\end{array}$ \\
\hline & mass transfer coefficient between & \\
\hline
\end{tabular}

liquid and air

$\begin{array}{lll}\mathrm{G}^{\prime}{ }_{\mathrm{a}} & \begin{array}{l}\text { superficial mass velocity of dry } \\ \text { air }\end{array} & \mathrm{kg} / \mathrm{m}^{2} \mathrm{~s} \\ \mathrm{G}_{1}{ }_{1} & \text { superficial mass velocity of } & \mathrm{kg} / \mathrm{m}^{2} \mathrm{~s}\end{array}$

$\mathrm{Y}$ moisture content in liquid $\mathrm{kg} \mathrm{H}_{2} \mathrm{O}$ / desiccant

$\mathrm{T}_{\mathrm{a}} \quad$ Temperature of air $\quad{ }^{\circ} \mathrm{C}$

$\mathrm{T}_{\text {ref }} \quad$ Temperature reference $\quad{ }^{\circ} \mathrm{C}$

$\mathrm{T}_{1} \quad$ Temperature Liquid Desiccant $\quad{ }^{\circ} \mathrm{C}$

h heat transfer coefficient between $\quad \mathrm{W} / \mathrm{m}^{2} \mathrm{~K}$

$\mathrm{q}_{\mathrm{b}} \quad$ binding energy of moisture in the $\mathrm{J} / \mathrm{kg}$ of liquid desiccant

L Height of packed bed $\quad \mathrm{m}$

$\mathrm{P} \quad$ Pressure $\mathrm{kPa}$

$\mathrm{P}_{\mathrm{s}} \quad$ Saturation Pressure of liquid $\quad \mathrm{kPa}$

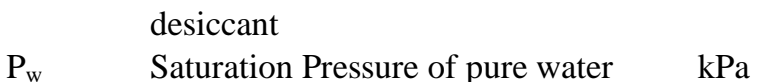

X Dimensionless Height of packed -

Greek.

$\lambda \quad$ latent heat of evaporation for $\quad \mathrm{J} / \mathrm{kg}$

$\rho_{\mathrm{a}} \quad$ Density of air $\mathrm{kg} / \mathrm{m}^{3}$

$\rho_{1} \quad$ Density of liquid desiccant $\quad \mathrm{kg} / \mathrm{m}^{3}$

$\phi \quad$ Equilibrium relative humidity

\section{CONFLICT OF INTEREST}

The authors declare no conflict of interest.

\section{REFERENCES}

[1] E. DeNicola, O. S. Aburizaiza, H. Khwaja and D. O. Carpenter, "Climate Change and Water Scarcity: The Case of Saudi Arabia," Annals of Global Health, vol. 81, no. 3, pp. 342-353, 2015.

[2] M. M. Mekonnen and A. Y. Hoekstra, "Four billion people facing severe water scarcity," Science Advances, vol. 2, no. 2, pp. 1-6, 2016.

[3] L. S. Pereira, I. Cordery and I. Iacovides, Coping with Water Scarcity: Addressing the Challenges, Springer, 2009.

[4] M. Berrittella, A. Y. Hoekstra, K. Rehdanz, R. Roson and R. S. Tol, "The economic impact of restricted water supply: A computable general equilibrium analysis," Water Research, vol. 41, pp. 1799-1813, 2007.

[5] M. B. McElroy, The Atmospheric Environment: Effects on Human Activity, Princeton University Press, 2002.

[6] R. V. Wahlgren, "Atmospheric Water Vapour Processor Designs For Potable Water Production: A Review," Water Research, vol. 35, no. 1, pp. 1-22, 2001.

[7] T. Anbarasu and S. Pavithra, "Vapour Compression Refrigeration System Generating Fresh Water from Humidity In the Air," in Chennai and Dr.MGR University Second International Conference on Sustainable Energy and Intelligent System, Chennai, 2011.

[8] A. Nandy, S. Saha, S. Ganguly and S. Chattopadhyay, "A Project on Atmospheric Water Generator with the Concept of Peltier Effect," International Journal of Advanced Computer Research, vol. 4, no. 15, pp. 481-486, 2014.

[9] T. Ming, T. Gong, R. K. de Richter, Y. Wu and W. Liu, "A moist air condensing device for sustainable energy production and water generation," Energy Conversion and Management, vol. 138, pp. 638-650, 2017.

[10] D. Bergmair, S. J. Metz, H. C. de Lange and A. A. van Steenhoven, "System analysis of membrane facilitated water generation from air humidity," Desalination, vol. 339, pp. 26-33, 2014.

[11] P. R. Burns, J. W. Mitchell and W. A. Beckman, "Solar Hybrid Desiccant Cooling Systems in Supermarket Applications," in Intersol Eighty Five, Oxford, Pergamon, 1986, pp. 700-706.

[12] H. Qi, T. Wei, W. Zhao, B. Zhu, G. Liu, P. Wang, Z. Lin, X. Wang, X. Li, X. Zhang and J. Zhu, "An Interfacial Solar-Driven Atmospheric Water Generator Based on a Liquid Sorbent with Simultaneous Adsorption-Desorption," Advanced 
Materials, vol. 31, pp. 1-9, 2019.

[13] S. Srivastava and A. Yadav, "Water generation from atmospheric air by using composite desiccant material through fixed focus concentrating solar thermal power," Solar Energy, vol. 169, pp. 302-315, 2018.

[14] X.-W. Li, X.-S. Zhang, G. Wang and R.-Q. Cao, "Research on ratio selection of a mixed liquid desiccant: Mixed $\mathrm{LiCl}-\mathrm{CaCl} 2$ solution," Solar Energy, vol. 82, pp. 1161-1171, 2008.

[15] X. H. Liu, K. Y. Qu and Y. Jiang, "Empirical correlations to predict the performance of the dehumidifier using liquid desiccant in heat and mass transfer," Renewable Energy, vol. 31, pp. 1627-1639, 2006.

[16] S. A. Abdul-Wahab, Y. H. Zurigat and M. K. Abu-Arabi, "Predictions of moisture removal rate and dehumidification effectiveness for structured liquid desiccant air dehumidifier," Energy, vol. 29, pp. 19-34, 2004.

[17] Y. Luo, H. Yang, L. Lu and R. Qi, "A review of the mathematical models for predicting the heat and mass transfer process in the liquid desiccant dehumidifier," Renewable and Sustainable Energy Reviews, vol. 31, pp. 587-599, 2014.

[18] S. Jain and P. K. Bansal, "Performance analysis of liquid desiccant dehumidification systems," International Journal of Refrigeration, vol. 30, pp. 861-872, 2007

[19] T. W. Chung, "Predictions of moisture removal efficiencies for packed-bed dehumidification systems," Gas Separation \& Purification, vol. 8, no. 4, pp. 265-268, 1994.

[20] K. Onda, H. Takeuchi and Y. Okumoto, "Mass Transfer Coefficients Between Gas and Liquid Phases in Packed Columns," Journal of Chemical Engineering of Japan, vol. 1, no. 1, pp. 56-62, 1968.

[21] P. Gandhidasan, C. F. Kettleborough and M. R. Ullah, "Calculation of Heat and Mass Transfer Coefficients in a Packed Tower Operating With a Desiccant-Air Contact System," Journal of Solar Energy Engineering, vol. 108, pp. 123-128, 1986.

[22] V. Oberg and D. Y. Goswami, "Experimental Study of the Heat and Mass Transfer in a Packed Bed Liquid Desiccant Air Dehumidifier," Journal of Solar Energy Engineering, vol. 120, pp. 289-297, 1998.

[23] P. Gandhidasan, "Estimation of the Effective Interfacial Area in Packed-Bed

\section{AUTHORS PROFILE}

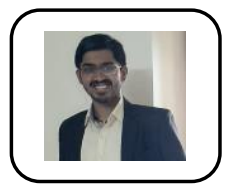

Aayush Bendre was born in 1999. He is pursuing his B.Tech in Chemical Engineering from Vishwakarma Institute of Technology, Pune (Affiliated to Savitribai Phule Pune University (SPPU)). He has two conference papers in International and National Conferences. His research interests are mathematical modelling, process control and

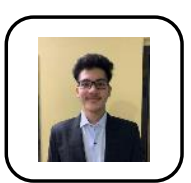
optimization.

Hardik Birla was born in year 2001. He is pursuing his B. Tech in chemical engineering from VIT, Pune. He has a patent and a paper in an international journal which goes by the name - Water purification using coagulant, flocculant and disinfectant. His work interests are petrochemicals, plant cost estimation and management.

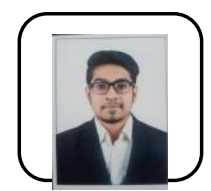

Chetan Choudhary was born in 2001. He is currently pursuing B.Tech. in Chemical Engineering at Vishwakarma Institute of Technology, Pune (registered with University of Pune) and will complete his graduation in 2022.He has about two papers published in International journals and presented one paper in international conference. His research interests are process control, optimization, materials sciences and Biotechnology.

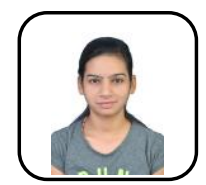

Gayatri Pralhad Potbhare born on 23rd April 2000. She is currently persuading her B.Tech in Chemical Engineering from Vishwakarma institute of technology, Pune. She has presented a paper in International Conference on Environmental Engineering (ICEE-2019) in January 2019. She has one paper published a paper on UV-visible spectroscopy of Fenugreek extract. Her research interest are applied science, chemistry, food technology and Polymer technology.

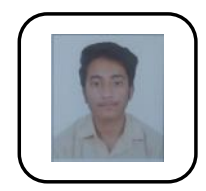

Burhanuddin Jawadwala was born in 2000. He is pursuing his B.Tech in Chemical Engineering from Vishwakarma Institute of Technology, Pune (Affiliated to Savitribai Phule Pune University (SPPU)). He has one
Liquid Desiccant Contactors," Industrial \& Engineering Chemistry Research, vol. 42, pp. 3420-3425, 2003.

[24] A. M. Radhwan, H. N. Gari and M. M. Elsayed, "Parametric Study of a Packed Bed Dehumidifier/Regenerator using CaCl2 Liquid Desiccant," Renewable Energy, vol. 3, no. 1, pp. 49-60, 1993.

[25] Occidental Chemical Corporation, "Calcium Chloride A Guide to Physical Properties".

[26] P. Bogacki and L. F. Shampine, "A 3(2) Pair of Runge - Kutta Formulas," Applied Mathematics Letters, vol. 2, no. 4, pp. 321-325, 1989.

[27] R. E. Treybal, Mass-Transfer Operations, Singapore: McGraw-Hill Book Company, 1981.

[28] M. M. Hammad, R. I. El-Ghanam, R. Y. Sakr and S. S. Ayad, "Experimental Study for Compact Liquid Desiccant Dehumidifier/Regenerator System," Engineering Research Journal, vol. 116, pp. M1-M28, 2008.

[29] B. Hardy, "ITS-90 formulations for vapor pressure, Frostpoint Temperature, Dewpoint Temperature, and Enhancement factors in the range -100 to $+100 \mathrm{c}, "$ in Third International Symposium on Humidity \& Moisture, London, 1998.

conference paper in a National Conferences. His research interests are in petroleum engineering, nanotechnology and optimization.

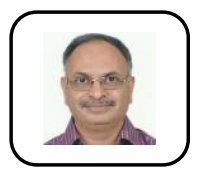

Satish R. Inamdar was born in 1960 . He obtained his M.Tech. in Chemical Engineering and Ph.D. in Chemistry from IIT Bombay and National Chemical Laboratory (registered with University of Pune) in April 1986 and February 1991 respectively. Later he was a post-doctoral fellow in process control and then a senior project engineer in optimization at National University of Singapore for five years. He obtained another Ph.D. Chemical Engineering in January 2014 from National Chemical Laboratory registered with Savitribai Phule Pune University (SPPU). He has about twenty seven papers published in International journals and about sixty conference papers in International and National conferences. His research interests are nonlinear science, process control, optimization, systems biology, and metamaterials. 